\title{
Natural compound Oblongifolin C confers gemcitabine resistance in pancreatic cancer by downregulating Src/MAPK/ERK pathways
}

\author{
Yang $\mathrm{Li}^{1,2}$, Zhichao Xi ${ }^{1,2}$, Xiaoqiong Chen ${ }^{1,2}$, Shuangfan Cai ${ }^{1,2}$, Chen Liang ${ }^{3}$, Zhen Wang ${ }^{3}$, Yingyi Li ${ }^{3}$, Hongsheng Tan ${ }^{1,2}$, \\ Yuanzhi Lao $\mathbb{B}^{1,2}$ and Hongxi Xu,
}

\begin{abstract}
Gemcitabine (GEM)-induced drug resistance is the major reason for the failure of chemotherapy in pancreatic cancer (PC). In this study, we found that Oblongifolin C (OC) efficiently inhibited PC cell proliferation by inducing GO/G1 arrest and apoptosis. Also, our mechanism study demonstrated that OC re-sensitized the GEM-resistant PC cells through the ubiquitin-proteasome-dependent degradation of Src, and then downregulating the MAPK pathway. Knockdown of Src plus OC resulted in a greater inhibitory effect in GEM-resistant PC cells. In contrast, Src overexpression reversed OCmediated chemosensitization, thereby implicating Src in the action of OC. Moreover, our in vivo study showed that OC suppressed the tumor growth via the downregulation of Src, and enhanced the chemosensitivity of GEM-resistant PC to GEM. Overall, our results have revealed that OC is applicable as a promising agent for overcoming GEM-resistant PC, especially with aberrant Src expression.
\end{abstract}

\section{Introduction}

Pancreatic adenocarcinoma is the most lethal cancer and has a poor prognosis. Gemcitabine (GEM), a cytotoxic nucleoside analog, is the clinical standard chemotherapy for pancreatic cancer (PC). The development of GEM resistance leads to a low response to chemotherapy and remains a significant limitation to its use ${ }^{1}$. Thus, agents that reverse GEM resistance and improve the chemosensitivity of chemotherapy in PC are needed.

Src, a membrane-associated non-receptor tyrosine kinase, is commonly overexpressed in most late-stage

\footnotetext{
Correspondence: Yuanzhi Lao (laurence_ylao@163.com) or

Hongxi Xu (xuhongxi88@gmail.com)

${ }^{1}$ School of Pharmacy, Shanghai University of Traditional Chinese Medicine, Shanghai 201203, P. R. China

${ }^{2}$ Engineering Research Center of Shanghai Colleges for TCM New Drug Discovery, Shanghai 201203, P. R. China

Full list of author information is available at the end of the article

These authors contributed equally: Yang Li, Zhichao Xi

Edited by B. Zhivotovsky.
}

tumor tissues, and is an indicator of poor clinical prognosis $^{2-5}$. Thus, Src has been a drug development target, and a number of tyrosine kinase inhibitors are currently undergoing clinical evaluation as cancer therapies ${ }^{6,7}$. Dasatinib, a dual Abl/Src inhibitor, has been approved by the Food and Drug Administration for the treatment of chronic myelogenous leukemia ${ }^{8}$. Recently, a significant amount of data show that aberrant activation of Src contributes to chemotherapy drug resistance in different types of cancers ${ }^{9-11}$. Activated Src kinase is also correlated with colorectal carcinoma cell resistance, and Dasatinib, as an Src inhibitor, could inhibit this protein and restore the sensitivity of liver metastatic colorectal carcinoma to oxaliplatin ${ }^{12}$.

Natural compounds are the main resources of drug development. The natural polyphenolic compound gallic acid could re-sensitized EGFR tyrosine kinase inhibitors though the inhibition of Src-Stat3-mediated signaling ${ }^{13}$.

\section{(c) The Author(s) 2018}

(c) (i) Open Access This article is licensed under a Creative Commons Attribution 4.0 International License, which permits use, sharing, adaptation, distribution and reproduction cc) in any medium or format, as long as you give appropriate credit to the original author(s) and the source, provide a link to the Creative Commons license, and indicate if changes were made. The images or other third party material in this article are included in the article's Creative Commons license, unless indicated otherwise in a credit line to the material. If material is not included in the article's Creative Commons license and your intended use is not permitted by statutory regulation or exceeds the permitted use, you will need to obtain permission directly from the copyright holder. To view a copy of this license, visit http://creativecommons.org/licenses/by/4.0/. 
In this study, we have confirmed that Oblongifolin $\mathrm{C}$ (OC), a natural product isolated from Garcinia yunnanensis, efficiently inhibits cell proliferation and enhances the sensitivity of GEM-resistant PC in vitro and in vivo through downregulation Src/MAPK/ERK pathways. Our findings suggest that $\mathrm{OC}$ is a new promising candidate to overcome GEM resistance in PC with the aberrant expression of Src.

\section{Results}

$O C$ inhibits the proliferation of parental and GEM-resistant PC by inducing G0/G1 arrest and apoptosis

Our previous studies have been reported that OC exhibited multiple anticancer properties ${ }^{14-16}$. In this study, we first assessed the viability of five human PC cell lines, MIA PaCa-2, Capan-1, SW1990, PANC-1, and BxPC-3 upon OC treatment. As shown in Table 1, OC efficiently inhibited the proliferation of PC cells. Next, we induced MIA PaCa-2, Capan-1 into MIA-RES and Capan1-RES via serially increasing the GEM concentrations, respectively. The $\mathrm{IC}_{50}$ values of GEM in the MIA-RES and Capan-1-RES cells increased markedly, which were 184 and more than 44 folds compared with their parental PC cells, respectively (Fig. 1a, Supplementary Fig. 1A and Table 2). Interestingly, Fig. $1 \mathrm{~b}$ and supplementary $1 \mathrm{~B}$ showed that OC still displayed cytotoxic effects against MIA-RES and Capan-1-RES cells with $\mathrm{IC}_{50}$ values of 9.86 $\pm 0.41 \mu \mathrm{M}$ and $15.20 \pm 0.35 \mu \mathrm{M}$, respectively, at $48 \mathrm{~h}$. We then examined the cell cycle distribution and apoptosis using propidium iodide (PI) staining flow cytometric analysis. The results demonstrated that $\mathrm{OC}$ accumulated in the G0/G1 phase of MIA PaCa-2 (Fig. 1c and Supplementary Fig. 1C) and MIA-RES (Fig. 1d and Supplementary Fig. 1D) cells at $24 \mathrm{~h}$ in a dose-dependent manner, with G0/G1 cell numbers increasing significantly from $48.8 \%$ at $0 \mu \mathrm{M}$ OC to $59.2 \%$ at $6 \mu \mathrm{M}$ OC in MIA $\mathrm{PaCa}-2$ and from $48.9 \%$ at $0 \mu \mathrm{M}$ OC to $61.6 \%$ at $10 \mu \mathrm{M}$ OC in MIA-RES, respectively. After treatment with OC for $48 \mathrm{~h}$, a significant increase of Sub-G1 cells from 3.29\%

Table 1 IC 50 values of OC in five different pancreatic cancer cell lines

\begin{tabular}{lll}
\hline Cell line & $\mathbf{4 8} \mathbf{h}$ & $\mathbf{7 2} \mathbf{h}$ \\
\hline MIA PaCa-2 & $6.70 \pm 0.55$ & $5.68 \pm 0.67$ \\
Capan-1 & $13.11 \pm 0.22$ & $7.89 \pm 1.22$ \\
SW1990 & $22.15 \pm 0.33$ & $12.23 \pm 0.64$ \\
PANC-1 & $13.90 \pm 0.93$ & $8.04 \pm 0.41$ \\
BXPC-3 & $8.37 \pm 2.08$ & $6.97 \pm 0.21$ \\
\hline
\end{tabular}

$\mathrm{IC}_{50}$ values of OC were determined with CCK8 assay in five different human pancreatic cancer cell lines with different concentrations for $48,72 \mathrm{~h}$, calculated by GraphPad Prism 5 software. $I C_{50}$ values are shown as the mean \pm SD of three independent experiments to $40.0 \%$ was observed in MIA-RES, and a similar effect with less potency was exerted in MIA PaCa- 2 cells, with an increase from $1.62 \%$ to $28.2 \%$. And the images of indicative cells were photographed by confocal microscopy (Supplementary Fig. 1E).

We then were curious regarding how $\mathrm{OC}$ regulated cell cycle-related proteins. We found that $\mathrm{OC}$ treatment reduced the protein expression of cyclin D3, cyclin E1, and cyclin A, and CDKs 4 and 6 in a time- and dosedependent manner (Fig. 1e and f) in MIA-RES cells, as well as the protein level of p-Rb (Ser807/811) and the tumor suppressor proteins with different members of $\mathrm{Rb} /$ p105 and $\mathrm{Rb} 2 / \mathrm{p} 130$. In addition, OC decreased the protein level of E2F1, a transcription factor in both MIA-RES and MIA PaCa-2 cells (data not shown). Moreover, OC reduced the expression of $\mathrm{Bcl}-2$ and $\mathrm{Bcl}-\mathrm{xL}$, two antiapoptotic proteins, and activated the caspase- 3 and PARP protein levels in PC cells.

\section{OC inhibits Src/MAPK/ERK signaling in MIA-RES cells}

It has been reported that the aberrant activation of Src contributes to chemotherapy drug resistance in different types of cancers ${ }^{9-11}$. To investigate whether the abnormal expression of Src involves in GEM-resistant PC cells, we compared the protein expressions of Src tyrosine kinases and its downstream mitogen-activated protein kinases (MAPKs) between MIA PaCa-2 and MIA-RES cells. Src activation is required the autophosphorylation site of Tyr416, and negatively regulated through phosphorylation of tyrosine 530 (avian Tyr527). Figure 2a shows that Src activity is highly expressed and constitutively activated in MIA-RES cells with the overexpression of Src tyrosine 416 phosphorylation and the faint band of phosphorylated Tyr527, compared with the parental MIA PaCa-2 cells. Consistently, its downstream MAPK signaling pathway was also activated. Next, we examine the consequences of Src/MAPK signaling after OC treatment in both cell lines. As shown in Fig. 2b, the Src/MAPK/ERK phosphorylation levels and AKT activity were remarkably decreased in MIA-RES cells after treatment with $10 \mu \mathrm{M}$ OC, with or without $40 \mu \mathrm{M}$ GEM for $48 \mathrm{~h}$. Although treatment with lower doses of OC and GEM were less effective. In addition, OC could not modulate the parental MIA PaCa2 cells through downregulation Src/MAPK pathways. In addition, Figs. $2 \mathrm{c}$ and $2 \mathrm{~d}$ showed that $\mathrm{OC}$ inactivated the Src protein by phosphorylation of the negative regulatory tyrosine 527 and downregulation the expression of p-Src Tyr416. Meantime, OC inhibited the MAPKs and AKT activity in a time- and dose-dependent manner. These findings suggested that OC re-sensitized MIA-RES cells to GEM by downregulating Src/MAPK and AKT pathways. To elucidate the possible mechanism of OC against Src signal, immunofluorescence staining was applied to observe the translocation of Src in MIA-RES cells. As 

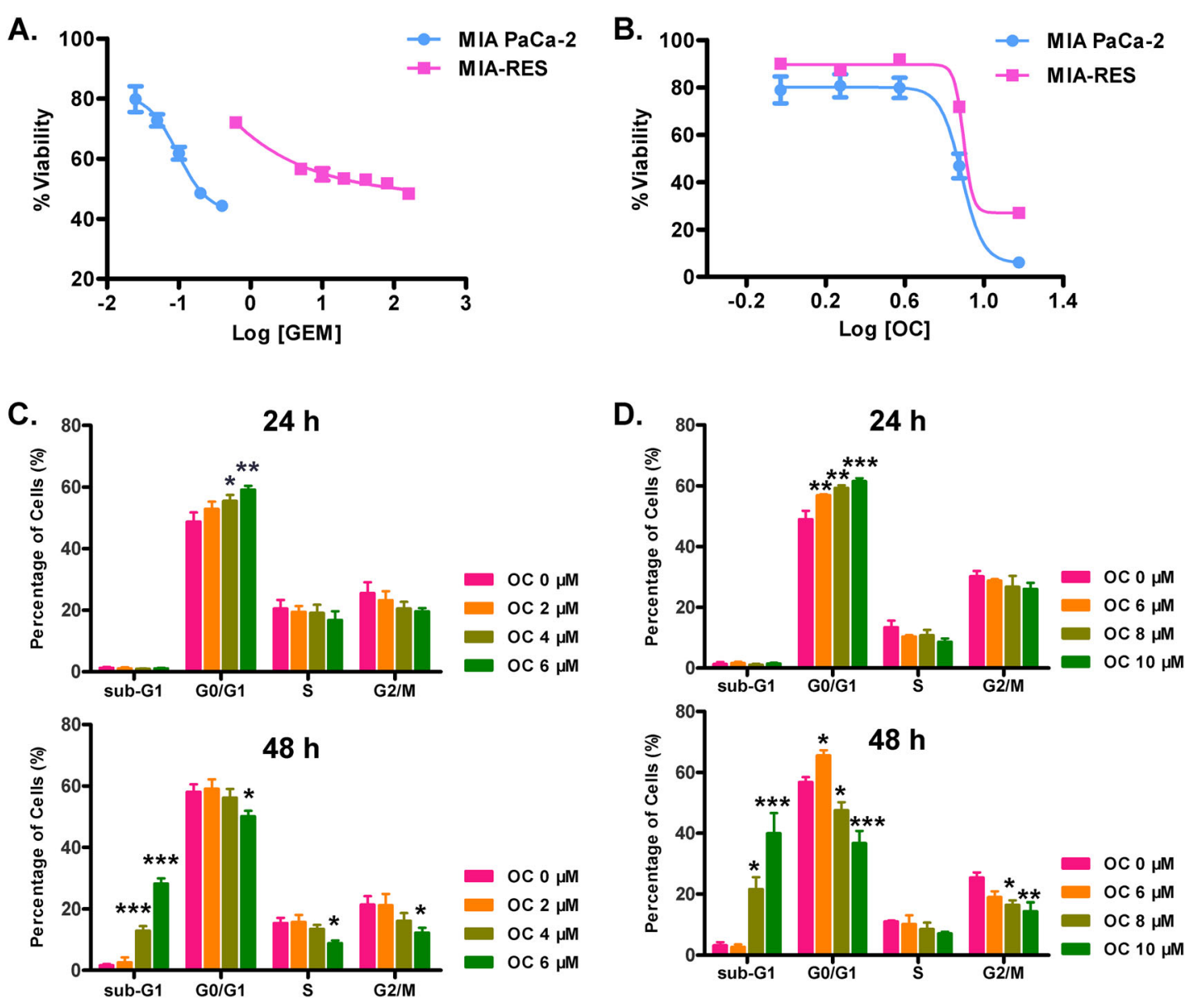

E.

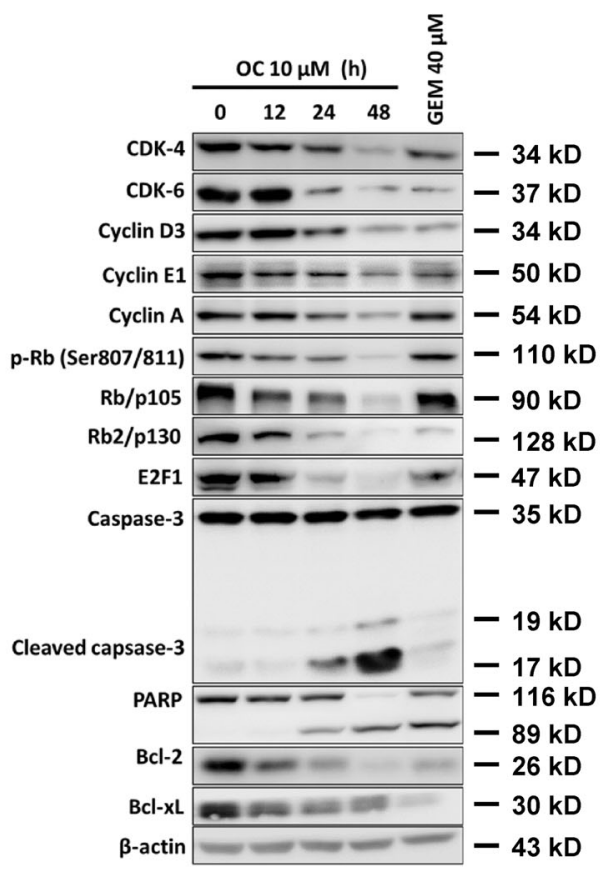

F.

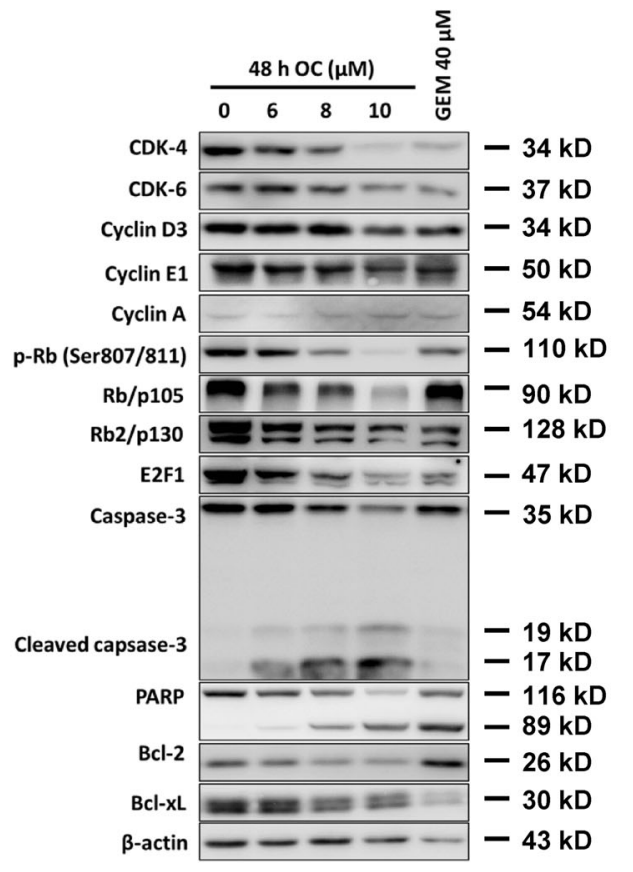

Fig. 1 (See legend on next page.) 
(see figure on previous page)

Fig. 1 OC inhibits the proliferation of parental and GEM-resistant PC cells by inducing G0/G1 arrest and apoptosis. The cell viability of the parental human pancreatic cancer cell line MIA PaCa-2 and its GEM-resistant cell line MIA-RES were exposed to different concentrations of GEM a and OC $\mathbf{b}$ for $48 \mathrm{~h}$, which were determined by a CCK8 assay. MIA PaCa-2 $\mathbf{c}$ and MIA-RES cells $\mathbf{d}$ were treated with indicated concentrations of OC for 24 , $48 \mathrm{~h}$, and subjected to flow cytometry analysis using propidium iodide staining. Data are expressed as the means \pm SD of triplicate assays compared with the controls. ${ }^{*} p<0.05,{ }^{* *} p<0.01$ and ${ }^{* * *} p<0.001$. MIA-RES cells were treated with OC for the indicated time periods e and concentrations $\mathbf{f}$, and subjected to western blotting analysis using the indicated antibodies. $\beta$-actin was used as the protein loading control.

Table 2 Comparison the sensitivity of $O C$ and gemcitabine towards parental and GEM-resistant PC cells

\begin{tabular}{lllll}
\hline Compound & MIA PaCa-2 & MIA-RES & Capan-1 & Capan-1-RES \\
\hline OC & $6.70 \pm 0.55$ & $9.86 \pm 0.41$ & $13.11 \pm 0.22$ & $15.20 \pm 0.35$ \\
GEM & $0.235 \pm 0.012$ & $43.38 \pm 17.31$ & $3.67 \pm 0.12$ & $>160$ \\
\hline
\end{tabular}

$\mathrm{IC}_{50}$ values of $\mathrm{OC}$ and gemcitabine were determined with CCK8 assay in MIA PaCa-2, Capan-1 cells, and its GEM-resistant subline MIA-RES, Capan-1-RES cells for $48 \mathrm{~h}$. $I C_{50}$ values are shown as the mean \pm SD of three independent experiments

shown in Fig. 2e, Src was dissociated from the membrane into the cytoplasm upon of $4 \mu \mathrm{M}$ OC treatment for $12 \mathrm{~h}$, suggesting that $\mathrm{OC}$ might act on the Src localization and was followed with the inhibition of Src. In addition, the transcription of Src was determined by qRT-PCR and Fig. 2f, which showed that the mRNA levels of Src did not decrease following $\mathrm{OC}$ treatment, suggesting that $\mathrm{OC}$ does not directly influence the transcription of Src.

\section{Knockdown of Src plus OC enhances the chemosensitivity to GEM in GEM-resistant human PC cells}

Considering the high expression levels of Src and its downstream MAPKs in GEM-resistant PC cells, we hypothesized that abnormal expression of $\mathrm{Src}$ was responsible for chemoresistance. To verify this hypothesis, Src-specific siRNA was used to knockdown Src in GEMresistant $\mathrm{PC}$ cells and its parental cells. As shown in Fig. 3a and supplementary Figure 2A, a pool of c-Src siRNAs, which include 4 target-specific 19-25 nt siRNAs, exhibited strong Src knockdown efficacies in both the mRNA expression and protein levels. Src activity was severely suppressed, with the autophosphorylated tyrosine 416 site downregulated in both Src-silencing cells. As predicated, the knockdown of the endogenous expression of Src significantly mediated the sensitization to cell death in MIA-RES cells when treated with OC or GEM (Fig. 3b). In Src knockdown cells, $40 \mu \mathrm{M}$ GEM treatment decreased the MIA-RES cell viability to $41.8 \%$, which is a nearly $20 \%$ reduction compared to the non-silenced cells (61.8\%). Interestingly, treatment with $10 \mu \mathrm{M} \mathrm{OC}$ in Src knockdown cells showed almost the same effects as $40 \mu \mathrm{M}$ GEM, the cell viability decreased from $66.5 \%$ in mock cells to $49.4 \%$ when treated with $10 \mu \mathrm{M}$ OC, whereas, co-treatment with $6 \mu \mathrm{M}$ of OC and $40 \mu \mathrm{M}$ GEM showed slight synergetic effects. Compared with MIA-RES cells, the parental MIA PaCa-2 cells showed a slightly inhibitory effect when treated with $\mathrm{OC}$ in Src-silencing cells (Fig. 3c). And similar results were obtained in Capan-1RES and Capan-1 cells, which are shown in Supplementary Figure 2C and 2D. To understand the mechanism underlying the enhanced antitumor effect of OC following the Src knockdown, we first assessed the mRNA level of Src. As shown in Figs. 3d and 3e, Src mRNA was slightly affected by OC treatment before and after silencing Src expression. Second, we also examined the activities of MAPKs in the indicated cells before and after OC treatment. It is due to that Src is associated with the promotion of MAPK-dependent cell proliferation and apoptosis ${ }^{17,18}$. Knockdown of the expression of Src significantly attenuated the activity of Src, with the decrease level of its autophosphorylated tyrosine 416 site, and also the expression of its downstream in MIA-RES cells. In addition, treatment of OC after silencing Src expression resulted in a greater inhibitory effect, with the expression of Src/MEK/ERK barely detectable (Fig. 3f). While comparing the protein expression of negative control and its Src-silenced MIA PaCa-2 cells, OC treatment had a minimal effect on the downstream protein of Src, which is insufficient to sensitize cells to death (Fig. 3g). Knockdown of Src had little effect on parental MIA PaCa-2 cells, one possibility is that the low basal expression of Src, and Src/MAPK pathways is not the major survival signaling.

Taken together, our data indicated that OC efficiently sensitized GEM-resistant PC cell death via downregulating $\mathrm{Src}$ expression, and it exhibited better effects after depleting Src expression in PC cells.

\section{Overexpression of Src reverts the effect of OC and enhances the chemoresistant of PC cells}

To further verify the effect of $\mathrm{OC}$ on Src kinase, we overexpressed Src to examine whether the effect of OC still existed. The transfection efficiencies of Src were shown in Fig. 4a and supplementary Figure 2B. Transfection of Src plasmid obviously increased the levels of mRNA expression and protein expression in PC cells. As showed in Figs. 4b, 4c and Supplementary 2E, 2 F, neither the Src plasmid nor the empty expression vector alone 
A.

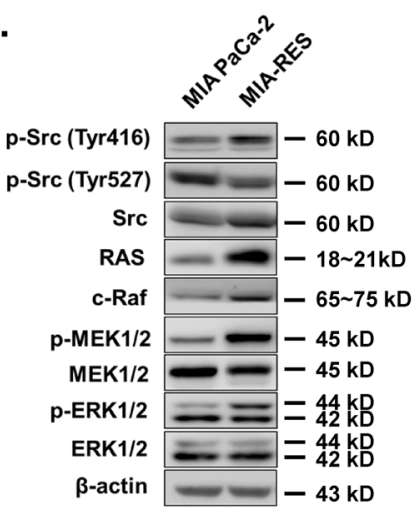

C.

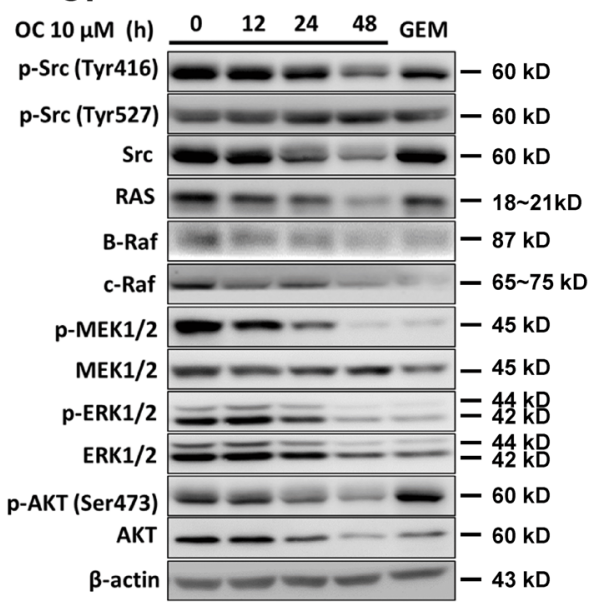

E.
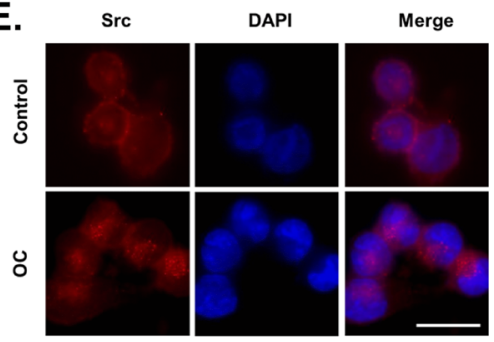

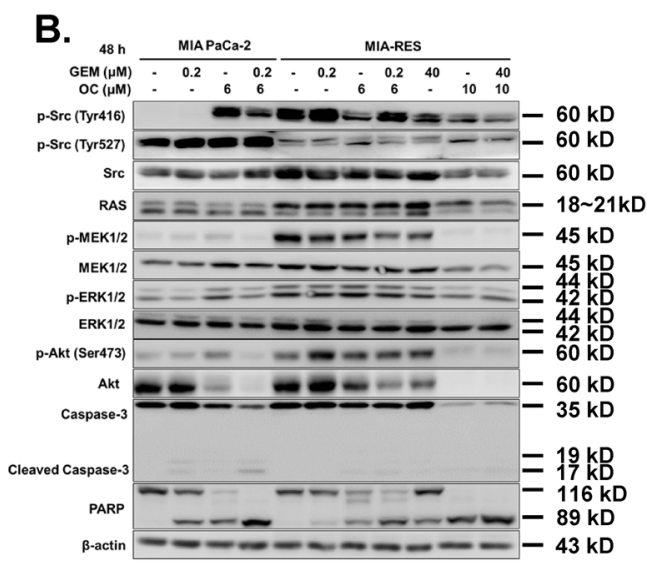

D.

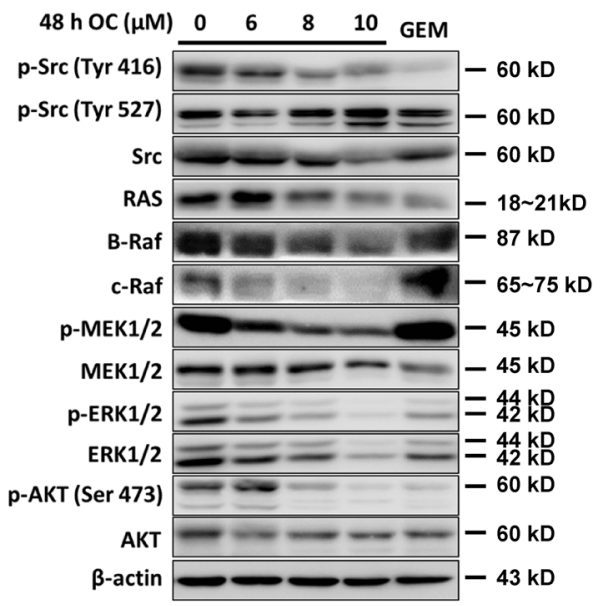

F.

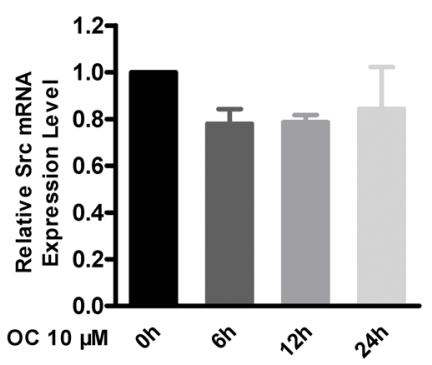

Fig. 2 OC downregulates the Src/MAPK/ERK signaling in GEM-resistant pancreatic cancer cells. a Comparison the levels of Src/p-Src (Tyr416, Tyr527), Ras, MEK/p-MEK1/2, and ERK/p-ERK1/2 by immunoblotting analysis in MIA PaCa-2 and MIA-RES cells. $\mathbf{b}$ The indicated cells were treated with GEM $(0.2 \mu \mathrm{M}$ or $40 \mu \mathrm{M})$, with or without $6 \mu \mathrm{M}$ or $10 \mu \mathrm{M}$ OC for $48 \mathrm{~h}$, then the cell lysates were analyzed by immunoblotting. $\beta$-actin was used as the protein loading control. c MIA-RES cells were treated with $10 \mu \mathrm{M} \mathrm{OC}$ for the indicated time periods $(0-48 \mathrm{~h})$ and indicated dose $(0-10 \mu \mathrm{M})$ of OC for $48 \mathrm{~h} \mathrm{~d}$, and treatment with $40 \mu \mathrm{M}$ GEM for $48 \mathrm{~h}$ as control. The cell lysates were analyzed by immunoblotting. e Immunofluorescence staining of Src in MIA-RES cells treated with or without $4 \mu \mathrm{M}$ OC for $12 \mathrm{~h}$. f Relative mRNA levels of Src in MIA-RES cells were determined by qRT-PCR, treated with $10 \mathrm{MM}$ of $\mathrm{OC}$ for the indicated time period $(0-24 \mathrm{~h})$.

significantly altered the observed cellular viability. Whereas, overexpression of Src increased chemoresistant to GEM both in parental and GEM-resistant PC cells. To a certain extent, Src overexpression also reverted the effect of $\mathrm{OC}$, or their combination. These results suggested that Src overexpression led to a low response of
GEM in PC and reversed OC-mediated chemosensitization. In addition, $\mathrm{OC}$ not only downregulate the ectopic protein expression of Src but also the mRNA level when transfection with exogenous Src plasmids into the two indicated cell lines (Figs. $4 \mathrm{~d}$ and $4 \mathrm{e}$ ). Figure $4 \mathrm{f}$ shows that Src overexpression activated MAPKs, and OC could 
A.
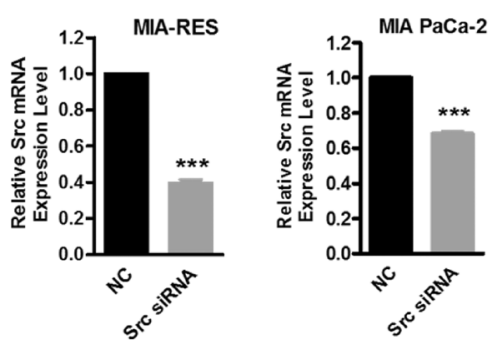

B.

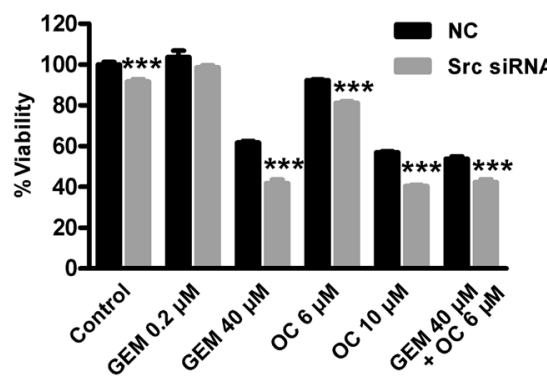

D.

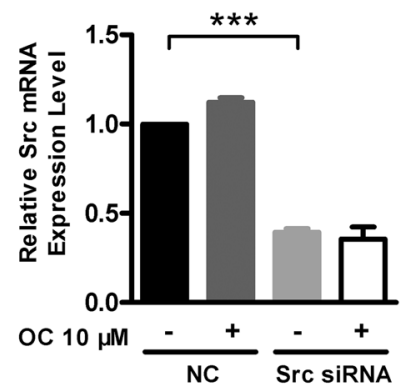

F. 24 h OC $10 \mu \mathrm{M}$ - $\frac{\mathrm{NC}}{-} \frac{\text { SrC SiRNA }}{-}$

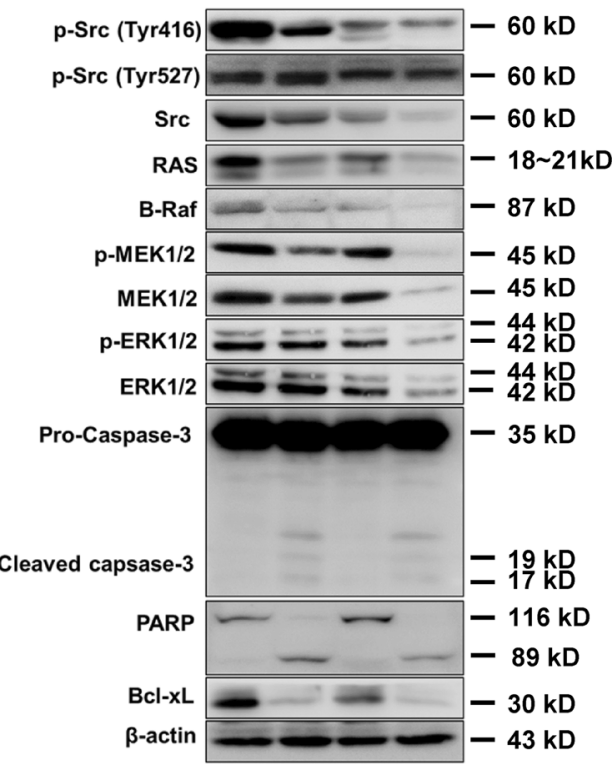

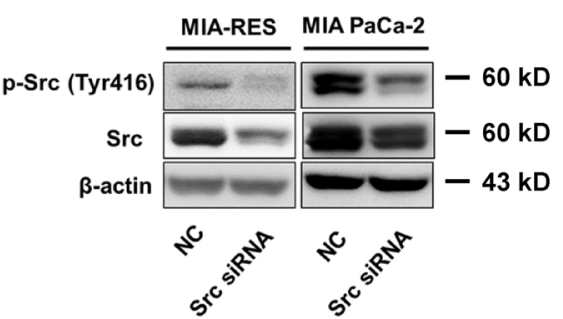

C.

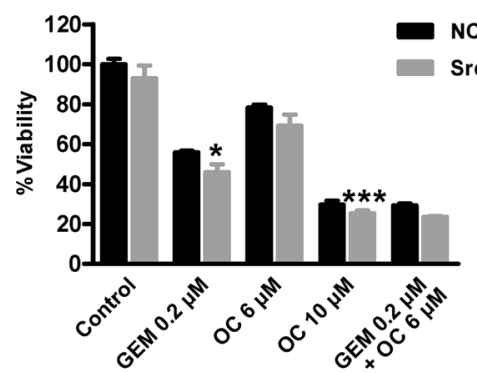

E.

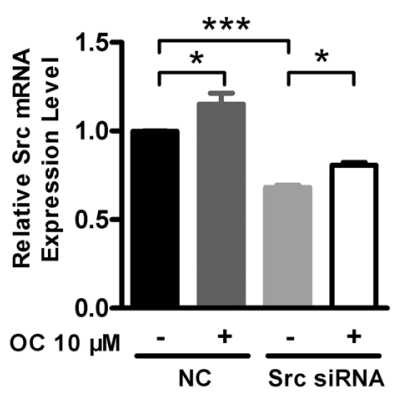

Fig. 3 (See legend on next page.) 
(see figure on previous page)

Fig. 3 Knockdown of Src plus OC increases chemosensitivity of MIA-RES cells. a MIA-RES and MIA PaCa-2 cells were transfected with nontargeting siRNA (NC) or Src-targeting siRNA (Src siRNA) for $48 \mathrm{~h}$. The expression of Src mRNA (left) and protein (right) were detected by qPCR and western blot analysis. TBP served as an endogenous control. $\beta$-actin was used as a loading control. Cell viability levels of MIA-RES $\mathbf{b}$ and MIA PaCa-2 cells $\mathbf{c}$ were measured by CCK8 assay in Src-silenced (Gray bars) and non-silenced cells (Black bars). Treatments are indicated at the bottom of the graph for $48 \mathrm{~h}$. Data represent the average of three independent experiments \pm standard deviation. ${ }^{*} p<0.05$ and ${ }^{* *} p<0.01{ }^{* *} p<0.001$. Relative Src MRNA expression levels of MIA-RES $\mathbf{d}$ and MIA PaCa-2 cells e were determined in Src-silenced and non-silenced cells, treated with or without $10 \mu \mathrm{M}$ OC for $24 \mathrm{~h}$. MIA-RES $\mathbf{f}$ and MIA PaCa-2 cells $\mathbf{g}$ were transfected with non-targeting siRNA (NC) or Src-targeting siRNA for $48 \mathrm{~h}$, followed by DMSO or OC treatment for $24 \mathrm{~h}$. Cell lysates were analyzed by immunoblotting. $\beta$-actin expression was used as a loading control.

partially block Src activity and MAPK signaling pathways, whereas OC exhibited little effect on MIA PaCa-2 cells (Fig. 4g). These findings suggest that OC-induced downregulation of Src have a critical role in inducing cell death of GEM-resistant PC cells.

\section{OC promotes Src protein degradation by the ubiquitin- proteasome pathway}

As OC sensitized the MIA-RES cells through the downregulation of Src expression, we further explored the mechanism that how OC regulated Src in PC cells. First, we examined the overall ubiquitination status upon $\mathrm{OC}$ treatment. Figures $5 \mathrm{a}$ and $5 \mathrm{~b}$ showed that the ubiquitination level was increased upon OC treatment in a doseand time-dependent manner. Several studies demonstrated that the active form of Src is required in a process of ubiquitin-proteasome-dependent degradation of $\mathrm{Src}^{19,20}$. Then, we exposed MIA-RES cells to the synthesis inhibitor by cycloheximide to investigate Src stability. The combined treatment of cycloheximide ( $\mathrm{CHX}$ ) with $\mathrm{OC}$ dramatically reduced protein stability of Src, with the active form of autophosphorylation tyrosine 416 site in predominant (Fig. 5c). Furthermore, we used MG132 to inhibit $26 \mathrm{~s}$ proteasome activity in MIA-RES cells. We found that the Src expression was enriched by OC treatment for $6 \mathrm{~h}$, suggesting that Src protein is degraded by the ubiquitin-proteasome pathway (Fig. 5d). We then performed immunoprecipitation to examine the directly effect of OC on Src ubiquitination. We overexpressed histagged Src in HEK293T cells and observed the ubiquitination level of Src upon OC treatment. As shown in Fig. 5e, $\mathrm{OC}$ increased the ubiquitination level of Src at $24 \mathrm{~h}$.

\section{OC suppresses orthotopic pancreatic tumor growth and improves the chemosensitivity of GEM in vivo}

To verify the inhibitory effect of $\mathrm{OC}$ in parental and GEM-resistant PC in vivo, we established two orthotopic mouse models using MIA PACA-2 and MIA-RES cells, respectively. No significant differences in body weights between the vehicle and $\mathrm{OC}$ treatment groups were observed, whereas the mice in GEM group were slightly decreased after day 23 (Fig. 6a). In the orthotopic animal models of parental PC cells, intraperitoneal administration of $20 \mathrm{mg} / \mathrm{kg}$ OC twice a day showed a similar effect as GEM, with a remarkable reduction of the xenograft tumor weight and tumor volume compared with the control mice (Figs. 6b, 6c and Supplementary Fig. 3A). In addition, immunohistochemical analysis revealed that $\mathrm{OC}$ reduced the number of proliferating $\mathrm{Ki}$ 67-positive cells and induced cleaved caspase-3 (Fig. 6d and Supplementary Fig. 3C).

To verify whether $\mathrm{OC}$ could enhance the chemosensitivity of GEM in GEM-resistant PC in vivo, orthotopic MIA-RES xenograft-bearing mice were divided into four groups: control, OC, GEM, and OC + GEM. Mice treated with GEM exhibited a tendency toward resistance effects, while OC + GEM exhibited better inhibitory effects on tumor growth than single drug treatment (Figs. 6f, $6 \mathrm{~g}$ and Supplementary Fig. 3B) with no obvious changes of body weight of the animals (Fig. 6e). Consistent with the immunohistochemical staining of $\mathrm{Ki}-67$ and cleaved caspase-3 (Fig. 6h and Supplementary Fig. 3D), OC activated apoptosis in $\mathrm{OC}$ treatment tumor tissue, and the lowest cell proliferation rate (Ki-67-positive cells) were appeared in the combination group. Also, we confirmed that $\mathrm{OC}$ treatment result in a similarly downregulation of Src expression in vivo, with the Src-positive cells in the OC treatment group decreased from $62.6 \%$ to $46.9 \%$, and a significant reduce $(4.9 \%)$ in combination group $(p<0.001)$.

Taken together, our results suggest that OC exert inhibitory effects on pancreatic tumor growth in vivo and improve the sensitivity of GEM through downregulating Src expression.

\section{Discussion}

Several publications mentioned that the natural products isolated from Garcinia species have been used for chemosensitizers in different types of cancer. $\alpha$-Mangostin, a natural xanthone derived from Garcinia mangostana L, selectively inhibited ABCG2-mediated drug transport and reversed MDR in ABCG2-overexpressing MDR cancer cells ${ }^{21}$. Li F et al. showed that Garcinol, a natural polyisoprenylated benzophenone derivative (PPAP), chemosensitized head and neck squamous cell carcinoma $\mathrm{b}$ negatively regulating constitutive cisplatininduced nuclear factor- $\mathrm{kB}$ activation and the expression of oncogenic gene product ${ }^{22}$. 
A.
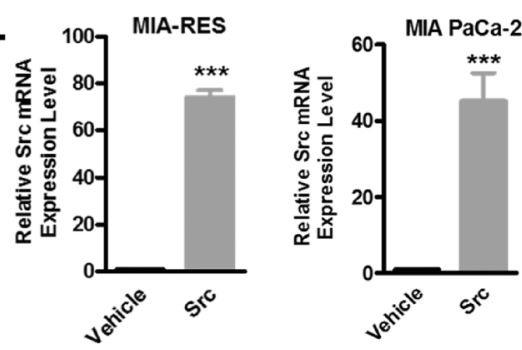

B.

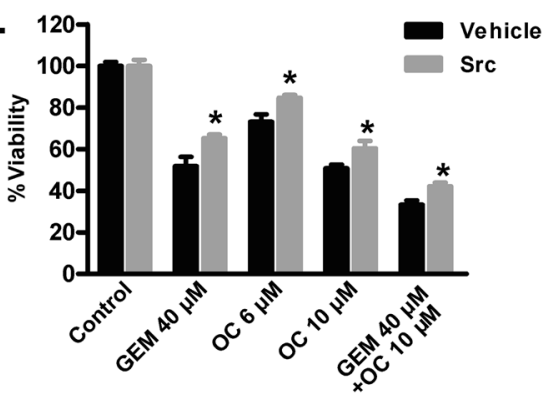

D.

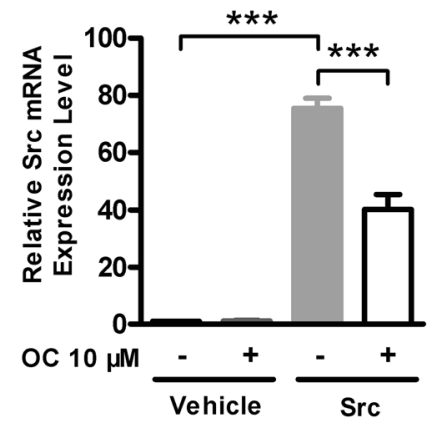

F.

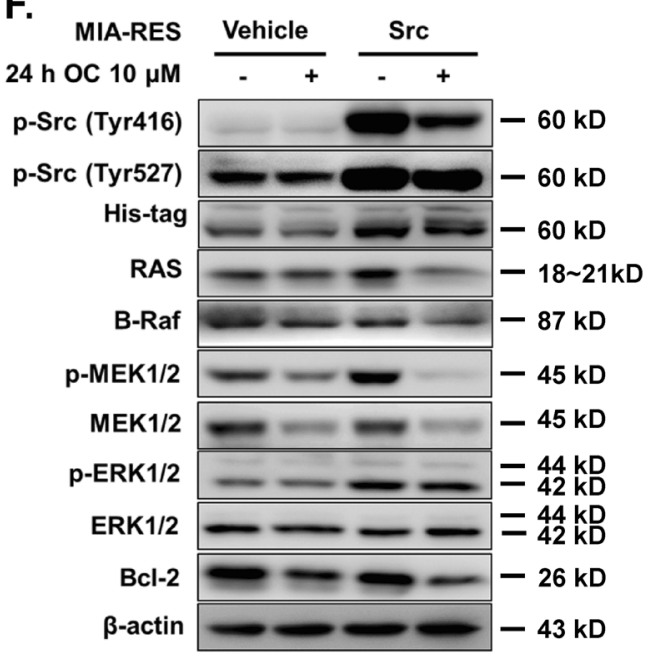

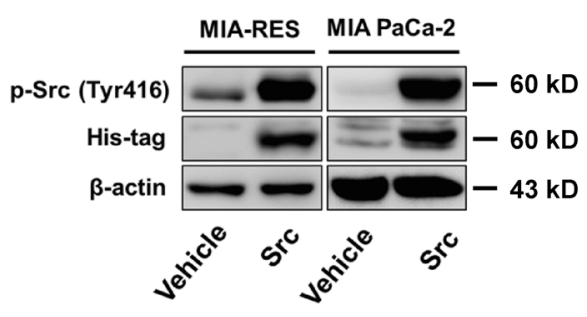

c.

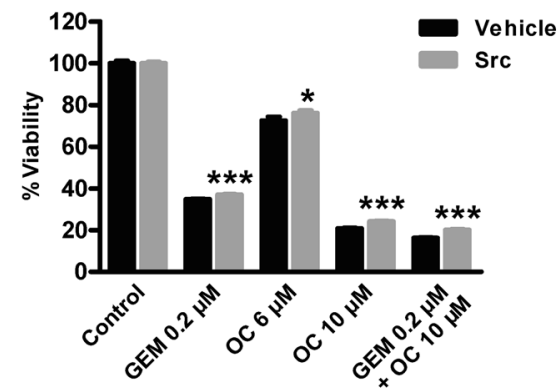

E.

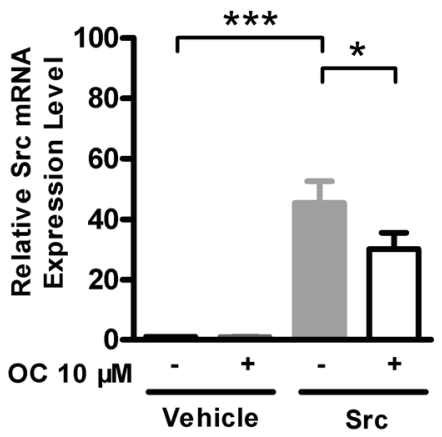

G.

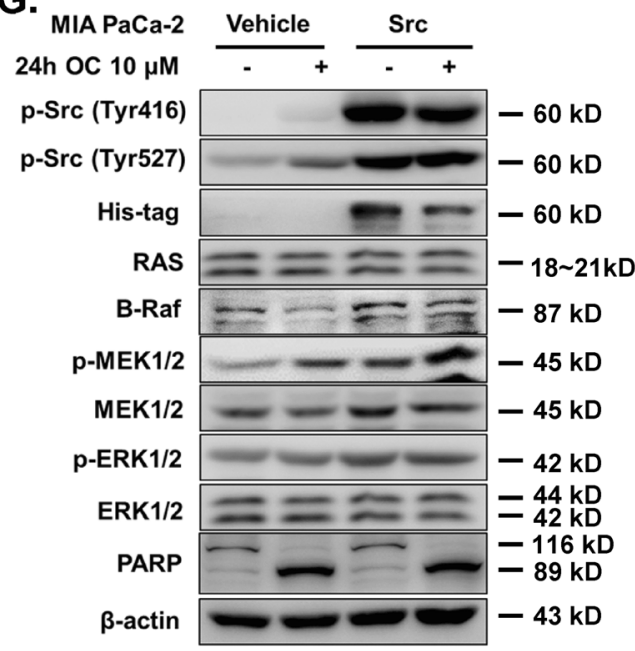

Fig. 4 Overexpression of Src reverts the effect of $O C$ and enhances the chemoresistant of pancreatic cancer cells. a MIA-RES and MIA PaCa-2 cells were transfected with $2 \mu \mathrm{g}$ Src plasmid or empty vector (Vehicle) for $24 \mathrm{~h}$. The expression of Src mRNA (left) and protein (right) were detected by GPCR and western blot analysis. TBP served as an endogenous control. $\beta$-actin was used as a loading control. Cell viability levels of MIA-RES $\mathbf{b}$ and MIA $\mathrm{PaCa}-2 \mathbf{c}$ were measured by CCK8 assay in Src overexpression (Gray bars) and empty vector (Black bars). Treatments are indicated at the bottom of the graph for $48 \mathrm{~h}$. Data represent the average of three independent experiments \pm standard deviation. ${ }^{*} p<0.05$ and ${ }^{* *} p<0.01{ }^{* * *} p<0.001$. Relative Src mRNA expression levels of MIA-RES $\mathbf{d}$ and MIA PaCa-2 cells e were determined after transfected with empty or Src plasmid, followed by the treatment with or without $10 \mu \mathrm{M}$ OC for $24 \mathrm{~h}$. f MIA-RES and MIA PaCa-2 cells $\mathbf{g}$ were transfected with Src expression vector or empty vector for $24 \mathrm{~h}$, followed by DMSO or OC treatment for $24 \mathrm{~h}$. Cell lysates were analyzed by immunoblotting. $\beta$-actin expression was used as a loading control. 
A.

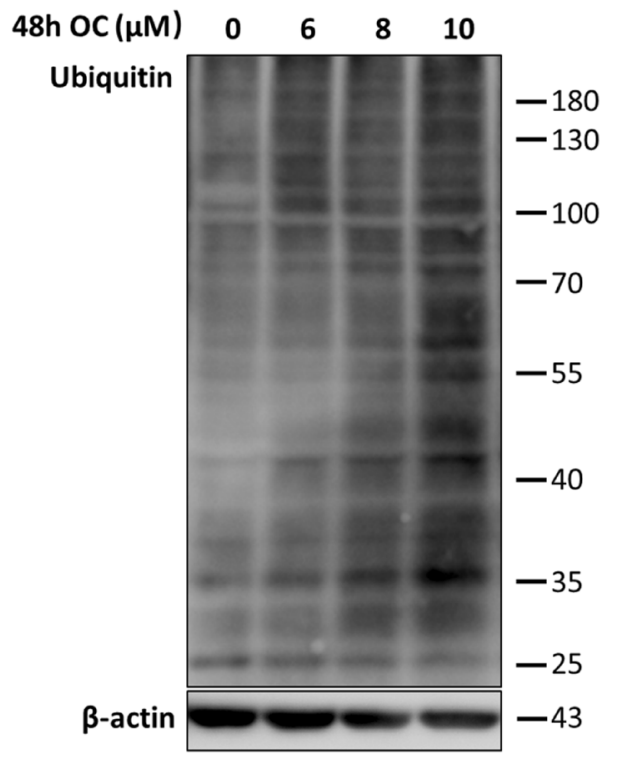

C.

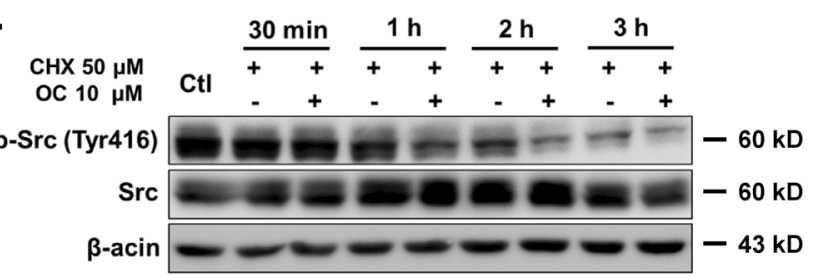

D.

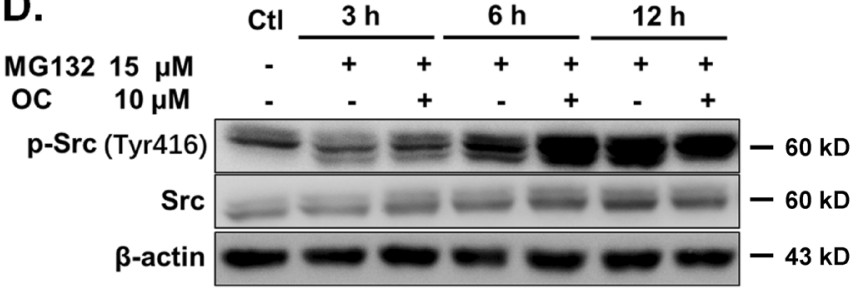

B. OC $10 \mu \mathrm{M}(\mathrm{h}) \quad 0 \quad 12 \quad 24 \quad 48$

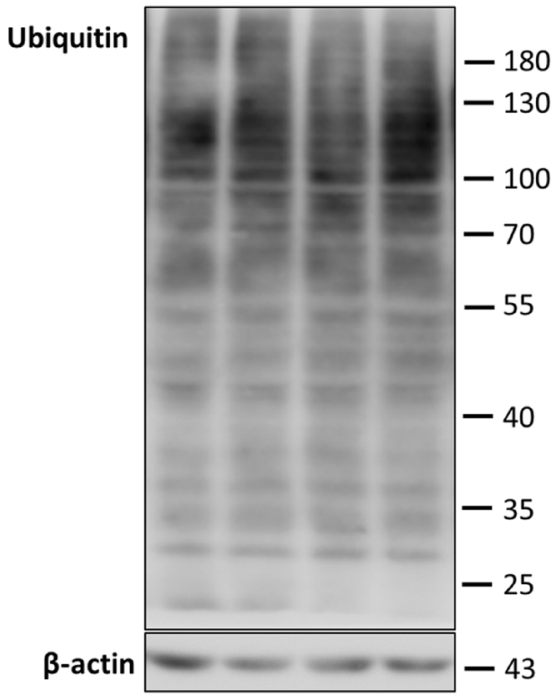

E. $24 \mathrm{~h} \mathrm{OC} 10 \mu \mathrm{M} \quad-\quad+$

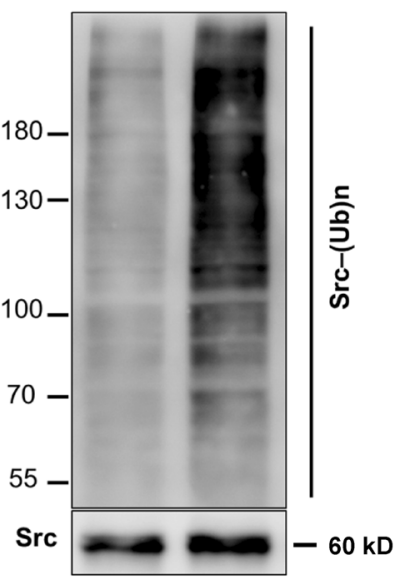

Fig. 5 OC promotes Src protein degradation by the ubiquitin-proteasome pathway. MIA-RES cells were treated with OC for the indicated dose $(0-10 \mu \mathrm{M}) \mathbf{a}$ and indicated time periods $(0-48 \mathrm{~h}) \mathbf{b}$, then the level of ubiquitination was detected by western blotting using an anti-ubiquitin antibody. c MIA-RES cells were treated with $50 \mu \mathrm{M}$ cycloheximide (CHX) with or without $10 \mu \mathrm{M} \mathrm{OC}$ for the indicated time and the cell lysates were analyzed by immunoblotting. $\beta$-actin served as a loading control. d MIA-RES cells were co-treated with $15 \mu \mathrm{M}$ MG132 with or without $10 \mu \mathrm{M}$ OC and harvested at $0,3,6,12$, and $24 \mathrm{~h}$ after treatment for western blotting analysis. $\beta$-actin served as a loading control. e MIA-RES cells were transfected with $2 \mu \mathrm{g}$ Src plasmid for $24 \mathrm{~h}$, and treated with $10 \mu \mathrm{M} \mathrm{OC}$ for $24 \mathrm{~h}$. The cells were treated with $15 \mu \mathrm{M} \mathrm{MG} 132$ for $6 \mathrm{~h}$ before collected, and $6 \mathrm{xHis-tagged}$ proteins of Src were purified with Ni-NTA Agarose beads, followed by western blotting analyses to detect the level of Src ubiquitination.

Src, a membrane-associated non-receptor tyrosine kinase, is constitutively active in pancreatic carcinoma tissue $^{23}$. More than $70 \%$ of oncogenes code for tyrosine kinases, so the inactivation of tyrosine kinases is a rational approach for PC therapy ${ }^{24,25}$. Previous studies also reported that Src kinase overactivity represents a chemoresistance mechanism and Src inhibition reverts chemoresistance in many cancer cells ${ }^{26-28}$. For these reasons, our study aims to focus on the Src inhibitor not only as an antitumor agent but also the potential ability to overcome the chemoresistance of acquired resistance PC.

In our study, we first demonstrated that $\mathrm{OC}$, a natural PPAP, exhibited a reversal effect on GEM-resistant PC through downregulating Src protein via ubiquitinproteasome pathway. While the transition of Src inhibitors to the clinic was limited by its toxicity, which was also mentioned in Johnson's publication ${ }^{29}$. In contrast, our study showed great growth inhibitory effects of OC in 
A.

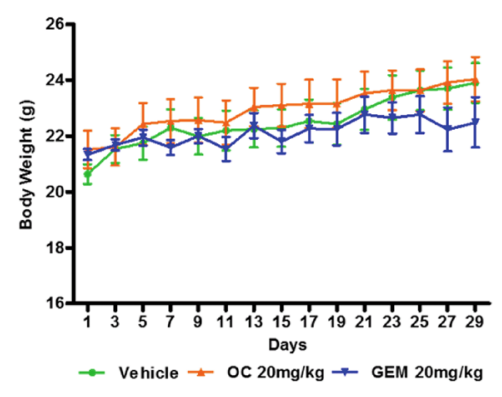

B.

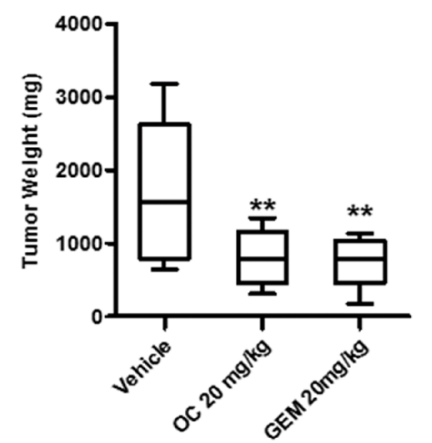

c.

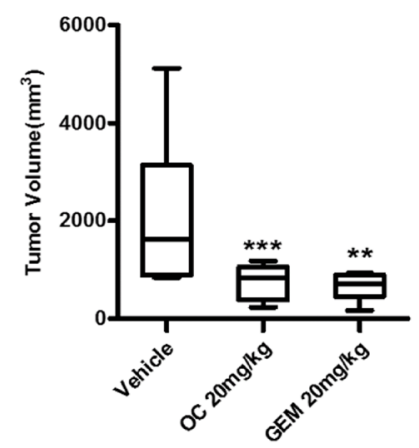

D.

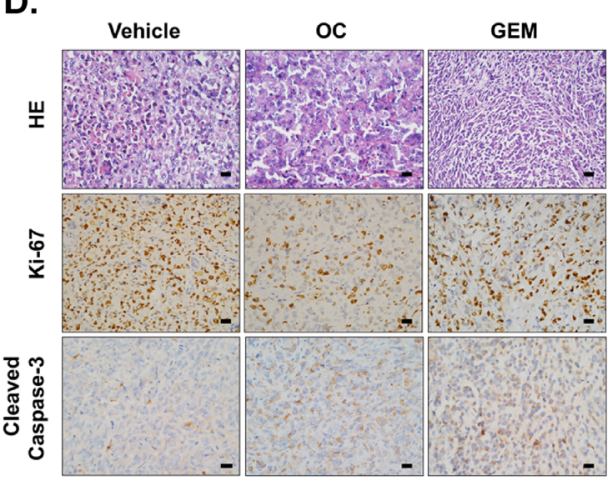

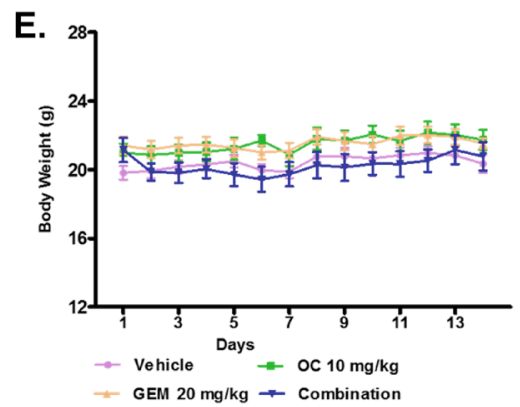

F. ${ }^{600}$

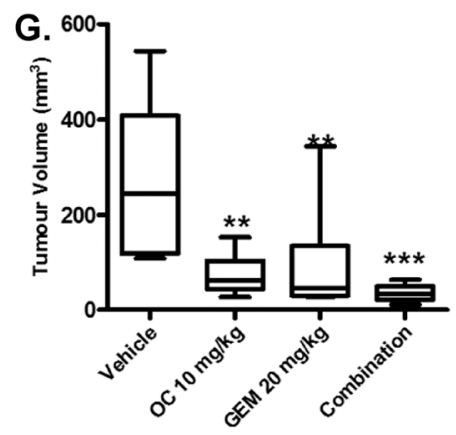

H. venicle oc GEM combination

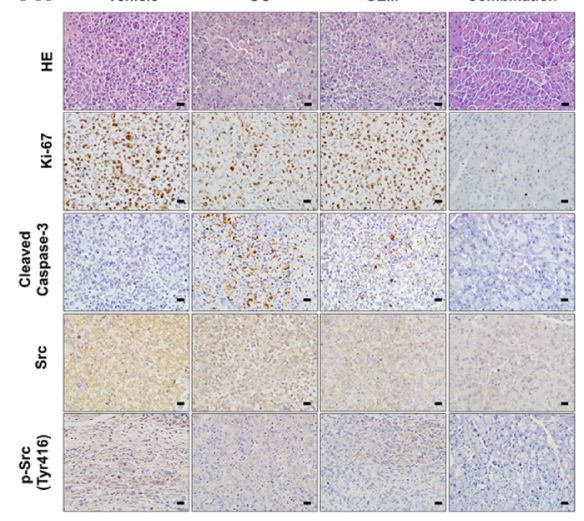

Fig. 6 (See legend on next page.) 
(see figure on previous page)

Fig. 6 OC suppresses orthotopic pancreatic tumor growth and improves the chemosensitivity of GEM in vivo. MIA PaCa- 2 cells $\left(1 \times 10^{6}\right.$ cells per mouse) were implanted directly into the pancreas of nude mice. One week later, the mice received intraperitoneal injections of either vehicle control (0.05\% DMSO in normal saline), $20 \mathrm{mg} / \mathrm{kg}$ OC every 2 days, or GEM $20 \mathrm{mg} / \mathrm{kg}$ twice a week. Body weights a of the animals were measured every other day. After four weeks, the mice were killed, tumor weight $\mathbf{b}$, and tumor volume $\mathbf{c}$ were measured. ${ }^{*} p<0.05,{ }^{* *} p<0.01,{ }^{* * *} p<0.001$ versus the corresponding control groups $(n=6)$. $\mathbf{d}$ Paraffin-embedded orthotopic tumor tissues sections were stained with HE or Ki-67, cleaved caspase-3 antibodies (Scale bar: $20 \mu \mathrm{m}$ ). For the GEM-resistant cellular orthotopic implantation, $1 \times 10^{6} \mathrm{MIA}$-RES cells were injected into the pancreas of each mice. One week later, the mice received intraperitoneal injections of either vehicle control (0.05\% DMSO in normal saline), OC (10 mg/kg) every day and GEM $(20 \mathrm{mg} / \mathrm{kg})$ twice a week alone or in combination with OC. Body weights e of the animals were measured every day. After 2 weeks of treatment, the mice were killed, tumor weight $\mathbf{f}$, and tumor volume $\mathbf{g}$ were measured. $\mathbf{h}$ Paraffin-embedded orthotopic tumor tissues sections were stained with HE, Ki-67, Src and p-Src (Tyr416), cleaved caspase-3 antibodies (Scale bar: $20 \mu \mathrm{m}$ ).

GEM-resistant PC without obvious side effects in nude mice. These results indicated that $\mathrm{OC}$ is a potential Src inhibitor in GEM-resistant PC.

In summary, our present study elucidated for the first time that $\mathrm{OC}$ represented an alternative therapy to overcome GEM-resistant PC growth by interfering with cellular tyrosine kinase Src both in vitro and in vivo.

\section{Material and Methods}

Cell cultures and development of GEM-resistant PC cells

Human pancreatic carcinoma cell lines MIA PaCa-2, PANC-1, and BxPC-3, Capan-1, SW1990 were purchased from the American Type Culture Collection. All the cell culture protocols and the development of MIA PaCa-2, Capan-1 into GEM-resistant MIA-RES and Capan-1-RES cells were followed as described previously ${ }^{30}$.

\section{Cell viability assay}

The cells were exposed to OC or GEM treatment for $48 \mathrm{~h}$ 1 day after seeding in 96-well plates. Cell viability was measured using the Cell Counting Kit (CCK8) (Yeasen, China), and the absorbance was measured at $470 \mathrm{~nm}$ using a microplate reader (FLUOstar Omega, BMG Labtech, Germany). The $\mathrm{IC}_{50}$ values were calculated from dose-response curves using GraphPad Prism 5 (La Jolla, California, USA).

\section{Propidium iodide staining for flow cytometry}

MIA PaCa-2 $\left(3 \times 10^{5}\right)$ and MIA-RES $\left(4 \times 10^{5}\right)$ cells were plated in a $60-\mathrm{mm}^{2}$ culture plate and maintained with $\mathrm{OC}$ with associated concentrations. After 24 and $48 \mathrm{~h}$, the cells were collected and fixed with $70 \%$ ethanol in phosphate-buffered saline (PBS) at $4{ }^{\circ} \mathrm{C}$. Then, the cells were resuspended with PBS, containing $100 \mu \mathrm{g} / \mathrm{mL}$ RNase (Sigma, R6513) and $20 \mu \mathrm{g} / \mathrm{mL}$ PI (Sigma, P4170), and incubated for $1 \mathrm{~h}$ at $37^{\circ} \mathrm{C}$. Finally, the cells were determined using a flow cytometer (BD Biosciences, San Jose, $\mathrm{CA}$ ) and analyzed using FlowJo software (version VX).

\section{Western blotting assay}

The detailed protocol has been described previously ${ }^{31}$. The information of antibodies was listed in Supplementary Table 1.

\section{Transfection}

c-Src siRNA (sc-29228; Santa Cruz, CA, USA) and negative control siRNA (sc-37007) were transfected with Lipofectamine RNAiMAX Reagents (Invitrogen) according to the manufacturer's instructions. The oligonucleotide sequences were listed in Supplementary Table 2.

The Src plasmid was cloned into the XhoI and KpnI restriction site of the GV219 vector (Genechem, Shanghai, China) and $2 \mu \mathrm{g}$ of plasmid was transfected for $24 \mathrm{~h}$ using Lipofectamine 2000 (Life technologies), as instructed by the manufacturer.

\section{RNA extraction and quantitative real-time PCR}

qRT-PCR was performed as described previously ${ }^{32}$. The PCR primers were listed in Supplementary Table 3. All the results were normalized to TATA box-binding protein (TBP).

\section{Immunofluorescent staining}

MIA-RES cells were allowed to adhere overnight and exposure to $4 \mu \mathrm{M}$ OC for $12 \mathrm{~h}$. Then, the cells were fixed with $4 \%$ paraformaldehyde/PBS, blocked with $10 \%$ BSA in PBS and incubated with anti-Src antibodies (1:50; CST\#2109), followed by Cy3-labeled secondary antibody (Beyotime, Shanghai, China). Images were visualized using an inverted fluorescent microscope (Olympus, Japan).

\section{Measurement of Src protein stability and ubiquitination}

MIA-RES cells were co-treated with $10 \mu \mathrm{M}$ OC with 50 $\mu \mathrm{M}$ CHX. After treatment for a given time, the cells were harvested for the western blot analysis of the Src protein level. For analysis of Src ubiquitination, HEK $293 \mathrm{~T}$ cells were transfected with his-tagged Src vectors. One day later, the cells were treated with $10 \mu \mathrm{M}$ OC for $24 \mathrm{~h}$, and treated with $15 \mu \mathrm{M}$ MG123 for $6 \mathrm{~h}$ before harvest. His-tagged Src was purified with Ni-NTA Agarose beads according to the manufacturers' protocols (Qiagen). The ubiquitination levels and the amount of Src-his-tagged protein in the immunoprecipitation product were detected by western blotting.

\section{Orthotopic tumor implantation in nude mice}

Five-week-old female BALB/c nude mice were purchased from the Experimental Animal Center of the 
Chinese Academy of Science (Shanghai, China) and kept in a pathogen-free environment. All animal experiments were performed in accordance with the national guideline as described previously ${ }^{33}$. For the parental GEM-sensitive cellular orthotopic implantation, $1 \times 10^{6}$ MIA PaCa-2 cells were injected into the pancreatic tail of each mouse. The mice were randomly divided into three groups (6 mice per group) for intraperitoneal treatment for 4 weeks with either vehicle control ( $0.5 \%$ dimethyl sulfoxide (DMSO), $0.5 \%$ Tween 80 ) (Group 1); OC, $20 \mathrm{mg} / \mathrm{kg}$ every 2 days (Group 2); or GEM, $20 \mathrm{mg} / \mathrm{kg}$ twice a week (Group 3).

For the GEM-resistant cellular orthotopic implantation, $1 \times 10^{6}$ MIA-RES cells were injected into the pancreas of each mice. Twenty-four mice were divided into four groups as follows for intraperitoneal treatment: vehicle control (0.5\% DMSO, 0.5\% Tween 80) (Group 1); OC, 10 $\mathrm{mg} / \mathrm{kg}$ every day (Group 2); GEM, $20 \mathrm{mg} / \mathrm{kg}$ twice a week (Group 3), combination OC $10 \mathrm{mg} / \mathrm{kg}$ every day and GEM $20 \mathrm{mg} / \mathrm{kg}$ twice a week (Group 4), begun 1 week after tumor implantation (day 1).

A few weeks later, the mice were sacrificed, and the tumor tissues were removed and subjected to immunohistochemical analysis. Tumor volumes were calculated using the following formula: (length $\times$ width $\times$ height $) \times \pi / 6$.

\section{Immunohistochemistry}

Tumors were fixed in 10\% neutral-buffered paraformaldehyde. Next, the samples were embedded in paraffin, stained with hematoxylin and eosin, cleaved caspase-3 (ab9664), Src (CST, 2109), p-Src Y418 (ab4816), and Ki-67 (EPITMICS, 2642-1). Finally, the sections were mounted with DPX Mountant (Sigma, 317616) for histological analysis.

\section{Statistical analysis}

The statistical software SPSS version 15.0 was used for the statistical analysis. Student's $t$-test was used for comparison between the two different groups, and ANOVA analysis was used for the multiple comparisons. All $p$ values $<0.05$ were considered statistically significant. Statistical significance was indicated $\left(* p<0.05 ;{ }^{* *} \mathrm{p}<0.01\right.$; $\left.{ }^{* * * * *} p<0.001\right)$, and all tests were two-tailed.

\section{Acknowledgements}

This work was supported by National Natural Science Foundation of China (NSFC81773951).

\footnotetext{
Author details

${ }^{1}$ School of Pharmacy, Shanghai University of Traditional Chinese Medicine, Shanghai 201203, P. R. China. ${ }^{2}$ Engineering Research Center of Shanghai Colleges for TCM New Drug Discovery, Shanghai 201203, P. R. China. ${ }^{3}$ Cancer Research Institute, Fudan University Shanghai Cancer Center, Department of Oncology, Shanghai Medical College, Fudan University, Shanghai, China
}

\section{Conflict of interest}

The authors declare no conflict of interest.
Publisher's note

Springer Nature remains neutral with regard to jurisdictional claims in published maps and institutional affiliations.

Supplementary Information accompanies this paper at (https://doi.org/ 10.1038/s41419-018-0574-1).

Received: 11 February 2018 Revised: 6 April 2018 Accepted: 6 April 2018 Published online: 10 May 2018

References

1. Li, D., Xie, K., Wolff, R. \& Abbruzzese, J. L. Pancreatic cancer. Lancet 363, 1049-1057 (2004)

2. Wiener, J. R. et al. Activated SRC protein tyrosine kinase is overexpressed in late-stage human ovarian cancers. Gynecol. Oncol. 88, 73-79 (2003).

3. Mandal, M. et al. Epithelial to mesenchymal transition in head and neck squamous carcinoma: association of Src activation with E-cadherin downregulation, vimentin expression, and aggressive tumor features. Cancer $\mathbf{1 1 2}$, 2088-2100 (2008).

4. Masaki, T. et al. pp60c-src activation in lung adenocarcinoma. Eur. J. Cancer 39, 1447-1455 (2003)

5. Aligayer, $\mathrm{H}$. et al. Activation of Src kinase in primary colorectal carcinoma: an indicator of poor clinical prognosis. Cancer 94, 344-351 (2002).

6. Kopetz, S. Targeting SRC and epidermal growth factor receptor in colorectal cancer: rationale and progress into the clinic. Gastrointest. Cancer Res. 1, S37-S41 (2007). 4Suppl 2.

7. Kopetz, S., Shah, A. N. \& Gallick, G. E. Src continues aging: current and future clinical directions. Clin. Cancer Res. 13, 7232-7236 (2007).

8. Montero, J. C., Seoane, S., Ocana, A. \& Pandiella, A. Inhibition of SRC family kinases and receptor tyrosine kinases by dasatinib: possible combinations in solid tumors. Clin. Cancer Res. 17, 5546-5552 (2011).

9. Stabile, L. P. et al. c-Src activation mediates erlotinib resistance in head and neck cancer by stimulating c-Met. Clin. Cancer Res. 19, 380-392 (2013).

10. Pengetnze, Y., Steed, M., Roby, K. F., Terranova, P. F. \& Taylor, C. C. Src tyrosine kinase promotes survival and resistance to chemotherapeutics in a mouse ovarian cancer cell line. Biochem. Biophys. Res. Commun. 309, 377-383 (2003).

11. George, J. A., Chen, T. \& Taylor, C. C. SRC tyrosine kinase and multidrug resistance protein-1 inhibitions act independently but cooperatively to restore paclitaxel sensitivity to paclitaxel-resistant ovarian cancer cells. Cancer Res. 65, 10381-10388 (2005)

12. Perez, M. et al. Dasatinib, a Src inhibitor, sensitizes liver metastatic colorectal carcinoma to oxaliplatin in tumors with high levels of phospho-Src. Oncotarget 7, 33111-33124 (2016).

13. Phan, A. N. et al. Gallic acid inhibition of Src-Stat3 signaling overcomes acquired resistance to EGF receptor tyrosine kinase inhibitors in advanced non-small cell lung cancer. Oncotarget 7, 54702-54713 (2016).

14. Feng, $C$. et al. A new anticancer compound, oblongifolin C, inhibits tumor growth and promotes apoptosis in HeLa cells through Bax activation. Int. J. Cancer 131, 1445-1454 (2012).

15. Lao, Y. et al. The natural compound oblongifolin $C$ inhibits autophagic flux and enhances antitumor efficacy of nutrient deprivation. Autophagy 10, 736-749 (2014)

16. $\mathrm{Xu}, \mathrm{W}$. et al. DNA damage and ER stress contribute to oblongifolin C-induced cell killing in Bax/Bak-deficient cells. Biochem. Biophys. Res. Commun. 457, 300-306 (2015).

17. $\mathrm{Wu}, \mathrm{H}$. et al. Inhibition of c-Src/p38 MAPK pathway ameliorates renal tubular epithelial cells apoptosis in db/db mice. Mol. Cell. Endocrinol. 417, 27-35 (2015).

18. Zhu, Y. et al. Gestrinone inhibits growth of human uterine leiomyoma may relate to activity regulation of ERalpha, Src and P38 MAPK. Biomed. Pharmacother. 66, 569-577 (2012).

19. Harris, K. F. et al. Ubiquitin-mediated degradation of active Src tyrosine kinase Proc. Natl. Acad. Sci. USA 96, 13738-13743 (1999).

20. Hakak, Y. \& Martin, G. S. Ubiquitin-dependent degradation of active Src. Curr. Biol. 9, 1039-1042 (1999).

21. Wu, C. P. et al. Alpha-mangostin reverses multidrug resistance by attenuating the function of the multidrug resistance-lainked ABCG2 transporter. Mol. Pharm. 14, 2805-2814 (2017). 
22. Li, F. et al. Garcinol sensitizes human head and neck carcinoma to cisplatin in a xenograft mouse model despite downregulation of proliferative biomarkers. Oncotarget 6, 5147-5163 (2015).

23. Lutz, M. P. et al. Overexpression and activation of the tyrosine kinase Src in human pancreatic carcinoma. Biochem. Biophys. Res. Commun. 243, 503-508 (1998).

24. Kleespies, A., Jauch, K. W. \& Bruns, C. J. Tyrosine kinase inhibitors and gemcitabine: new treatment options in pancreatic cancer? Drug. Resist. Updat. 9 1-18 (2006)

25. Duxbury, M. S., Ito, H., Zinner, M. J., Ashley, S. W. \& Whang, E. E. siRNA directed against c-Src enhances pancreatic adenocarcinoma cell gemcitabine chemosensitivity. J. Am. Coll. Surg. 198, 953-959 (2004).

26. Wu, Z. H. et al. Src Inhibition Can Synergize with Gemcitabine and Reverse Resistance in Triple Negative Breast Cancer Cells via the AKT/c-Jun Pathway. PLOS ONE 11, e0169230 (2016).

27. Ischenko, I. et al. Inhibition of Src tyrosine kinase reverts chemoresistance toward 5-fluorouracil in human pancreatic carcinoma cells: an involvement of epidermal growth factor receptor signaling. Oncogene 27, 7212-7222 (2008).
28. Duxbury, M. S., Ito, H., Zinner, M. J., Ashley, S. W. \& Whang, E. E. Inhibition of SRC tyrosine kinase impairs inherent and acquired gemcitabine resistance in human pancreatic adenocarcinoma cells. Clin. Cancer Res. 10, 2307-2318 (2004).

29. Johnson F. M., et al. A phase I study (CA180021-Segment 2) of dasatinib in patients (pts) with advanced solid tumors. J. Clin. Oncol 25, 14042 (2007).

30. Liang, $\mathrm{C}$. et al. MicroRNA-33a-mediated downregulation of Pim-3 kinase expression renders human pancreatic cancer cells sensitivity to gemcitabine. Oncotarget 6, 14440-14455 (2015).

31. Xi, Z. et al. Guttiferone $\mathrm{K}$ impedes cell cycle re-entry of quiescent prostate cancer cells via stabilization of FBXW7 and subsequent c-MYC degradation. Cell Death Dis. 7, e2252 (2016).

32. Zhang, L. et al. Nujiangexathone A, a novel compound from Garcinia nujiangensis, suppresses cervical cancer growth by targeting hnRNPK. Cancer Lett. 380, 447-456 (2016).

33. Shen, $\mathrm{K}$. et al. Guttiferone $\mathrm{K}$ suppresses cell motility and metastasis of hepatocellular carcinoma by restoring aberrantly reduced profilin 1. Oncotarget $\mathbf{7}$ 56650-56663 (2016). 